\title{
The Spatial Structure of the Annual Cycle in Surface Temperature: Amplitude, Phase, and Lagrangian History
}

\section{Citation}

McKinnon, Karen Aline, Alexander Robin Stine, and Peter John Huybers. 2013. "The Spatial Structure of the Annual Cycle in Surface Temperature: Amplitude, Phase, and Lagrangian History." Journal of Climate 26 (20): 7852-7862.

\section{Published Version}

doi:10.1175/JCLI-D-13-00021.1

\section{Permanent link}

http://nrs.harvard.edu/urn-3:HUL.InstRepos:13454553

\section{Terms of Use}

This article was downloaded from Harvard University's DASH repository, and is made available under the terms and conditions applicable to Open Access Policy Articles, as set forth at http:// nrs.harvard.edu/urn-3:HUL.InstRepos:dash.current.terms-of-use\#OAP

\section{Share Your Story}

The Harvard community has made this article openly available.

Please share how this access benefits you. Submit a story.

\section{Accessibility}


1 The spatial structure of the annual cycle in surface temperature:

2

3 Karen A. McKinnon*, Alexander R. Stine and Peter Huybers

Dept. of Earth and Planetary Sciences, Harvard University, Cambridge, Massachusetts

\author{
amplitude, phase, and Lagrangian history
}

KAREN A. MCKINNON*, ALEXANDER R. STINE AND PETER HUYBERS

*Corresponding author address: Karen A. McKinnon, Dept. of Earth and Planetary Sciences, Harvard University, 20 Oxford St., Cambridge, MA 02138.

E-mail: mckinnon@fas.harvard.edu 
5 The climatological annual cycle in surface air temperature, defined by its amplitude and 6 phase lag with respect to solar insolation, is one of the most familiar aspects of our climate 7 system. Here, we identify three first-order features of the spatial structure of amplitude and phase lag and explain them using simple physical models. Amplitude and phase lag (1) are broadly consistent with a land and ocean end-member mixing model, but (2) exhibit overlap between land and ocean, and, despite this overlap, (3) show a systematically greater lag over ocean than land for a given amplitude. Based on previous work diagnosing relative ocean or land influence as an important control on the extratropical annual cycle, we use a Lagrangian trajectory model to quantify this influence as the weighted amount of time that an ensemble of air parcels has spent over ocean or land. This quantity explains $84 \%$ of the space-time variance in the extratropical annual cycle, as well as features (1) and (2). All three features can be explained using a simple energy balance model with land and ocean surfaces and an advecting atmosphere. This model explains $94 \%$ of the space-time variance of the annual cycle in an illustrative mid-latitude zonal band when incorporating the results of the trajectory model. The basic features of annual variability in surface air temperature thus appear to be explained by the coupling of land and ocean through mean atmospheric circulation. 


\section{Introduction}

It has been long understood that the annual cycle in surface air temperature is largely controlled by the annual cycle in solar radiation, local surface conditions, and atmospheric circulation. Generally, oceanic climates have a small amplitude and large phase lag with respect to solar forcing, while continental climates have a large amplitude and small lag (Von Hann and Ward 1903), with additional structure associated with the direction and strength of prevailing winds (Ward 1906). This qualitative understanding of the systematic patterns in amplitude and lag of the annual cycle has also been supported by quantitative analysis, with a historical focus on obtaining a single measure of "continentality" that would reflect the relative influences of land and ocean.

Brooks (1917) used the land fraction in a series of concentric circles around a location as a predictor for the amplitude of the annual cycle, capturing the effects of nearby land or ocean, and Brooks (1918) went on to account for the direction of the prevailing winds. Similar methods aiming to determine the amplitude of the annual cycle from a regression of geographic variables were presented by Spitaler (1922), Brunt (1924), and Hela (1953). Other work focused instead on the lag of temperature behind solar radiation as a measure of continentality (Prescott and Collins 1951; van den Dool and Können 1981), but amplitude and lag were not unified into a single framework for describing continentality.

More recently, Stine et al. (2009) focused on the relationship between amplitude and phase lag of the annual cycle, and showed that observations of the annual cycle could be approximately described as a linear mixture of two sinusoids, interpreted as theoretical ocean and land end-members. This conceptual framework provided a link between amplitude and phase, and also demonstrated that each provides a slightly different picture of the spatial structure of the annual cycle (see Fig. 1a,b in Stine et al. 2009). They further demonstrated the important role of the prevailing winds; however, their description of the annual cycle was fundamentally algebraic.

A number of simple models based on energy balance principles have also been applied to 
reproducing the annual cycle in surface temperature. Thompson and Schneider (1979) used a two-layer zonal model with diffusive heat transport and reproduced the zonally-averaged amplitude of the annual cycle, but the modeled temperature lagged the observations by one to two months. North et al. (1983) expanded on the one-layer diffusive energy balance model of North and Coakley (1979) and North et al. (1981) to include realistic continental configurations, using heat capacity to distinguish between ocean, land, and coastal areas. Subsequent work used comparable models with application to the annual cycle, with comparable results (Hyde et al. 1989; Kim and North 1992). These previous models parameterized atmospheric heat transport as a diffusive process and, while they do capture much of the first-order structure in the annual cycle, do not account for the role of of atmospheric advection (e.g. Brooks 1918; van den Dool and Können 1981). The influence of advection on seasonality is readily discerned in the east-to-west structure across extratropical continents and oceans (Stine and Huybers 2012).

Here, we analyze spatial variability in the climatological annual cycle in surface temperature and seek to explain, using simple physical models, three of its primary features: a first-order structure consistent with the extratropical annual cycle as a mixture of ocean and land end-member sinusoids (Stine et al. 2009), an overlap in amplitude and phase between ocean and land annual cycles, and a non-unique relationship between amplitude and phase, where the ocean systematically has a later phasing for the same amplitude. While the first feature can be well-predicted by westward distance from the coast (Stine et al. 2009), explanation of both the second and third features requires a more complete framework. It will be demonstrated that these features emerge from distinct ocean and land heat capacities in conjunction with mean circulation patterns. 


\footnotetext{
${ }^{1}$ Code available at http://www.ncdc.noaa.gov/paleo/pubs/huybers2006b/huybers2006b.html
}

\section{Structure of the annual cycle}

We use monthly climatological temperature data from the Hadley Centre Climate Research Unit (HadCRU, Morice et al. 2012). The climatology is based on the period 1961-1990 and is reported at $5^{\circ}$ spatial resolution. Data are provided as monthly averages, which, given the Nyquist criterion that observing a sinusoid requires sampling at just less than half its period, is more than adequate to constrain the amplitude and phase of the annual cycle (Thompson 1995). For example, our tests using the long (> 30 years) extratropical records in the Global Historical Climatological Network (Menne et al. 2012) indicate an average correlation coefficient between estimates of phase lag and amplitude calculated using daily and monthly average temperatures of greater than 0.99 , and a root mean square difference across the domain of 0.07 days for phase lag and $0.05{ }^{\circ} \mathrm{C}$ for amplitude. Only gridboxes where the HadCRUT4 product (Morice et al. 2012) has at least five of the thirty years of observational data for all months of the year are included in the analysis. Each extratropical hemisphere is considered, but the tropics $\left(23^{\circ} \mathrm{N}-23^{\circ} \mathrm{S}\right)$ are excluded because the annual cycle there contains substantial twice-per-year variability, and variations in local incoming solar radiation are a less dominant control on surface temperature relative to higher latitudes.

Over $99 \%$ of the space-time variance in the annual cycle in surface air temperature across the extratropics can be explained by the annual Fourier component, allowing for efficient representation of the monthly climatology as its amplitude and phase. In order to account for differences in solar insolation, we define gain as the amplitude normalized by the latitudinally-variable amplitude of the annual Fourier component in solar insolation (Berger and Loutre 1991$)^{1}, \mathrm{G}(x, y)=A_{T}(x, y) / A_{\text {sun }}(y)$, and lag as the difference in phase between the annual Fourier component of temperature and insolation, $\lambda(x, y)=\phi_{T}(x, y)-\phi_{\operatorname{sun}}(y)$.

Gain and lag exhibit coherent spatial structure (Fig. 1). Gain is generally larger over Northern Hemisphere land masses, increases from west to east across continents, and increases more rapidly across North America than Eurasia. The smallest gains are found in 
the Southern Ocean and the North Atlantic, while the largest are in northeastern Eurasia. Lag exhibits a clearer land-ocean dichotomy, with an average lag of 28 days over land and 58 days over ocean. This structure can be efficiently represented in polar coordinates (Fig. 2), where gain is indicated by the distance from the origin, and lag by the angle measured counter-clockwise from the positive $\mathrm{x}$-axis. The $\mathrm{x}$-component is the gain that is in phase with the sun, and the y-component is the gain that is in quadrature with the sun. Polar coordinates offer the advantage that the mixing curve between two sinusoids is a straight line, and we use this representation to define three characteristics of the annual cycle:

(1) Linearity: The first-order structure in polar coordinates is linear with both the intercept and slope positive. This relationship is consistent with a mixing model framework wherein a continental component that has high gain and small lag is linearly combined with an oceanic component that has low gain and large lag (Stine et al. 2009).

(2) Overlap: Ocean and land values overlap for both lag and gain. Land gridboxes are found with smaller gains and larger lags than ocean gridboxes, and the converse. This overlap is not a result of the coarseness of the grid that we employ because it exists even after excluding all gridboxes that contain mixed ocean and land, as indicated by a one-degree land mask. For instance, the gain of the annual cycle is $47 \%$ larger in the East China Sea $\left(27.5^{\circ} \mathrm{N}, 127.5^{\circ} \mathrm{E}\right)$ than in central France $\left(47.5^{\circ} \mathrm{N}, 2.5^{\circ} \mathrm{E}\right)$, and the lag in southern Nunavut, Canada $\left(62.5^{\circ} \mathrm{N}, 97.5^{\circ} \mathrm{W}\right)$ is approximately five days longer than that in the middle of the Greenland Sea $\left(77.5^{\circ} \mathrm{N}, 2.5^{\circ} \mathrm{W}\right)$. More generally, $29 \%$ of the extratropical gridboxes that we analyze have gains ranging between the minimum land gain and maximum ocean gain, and $10 \%$ have lags ranging between the maximum land lag and the minimum ocean lag.

(3) Offset: For ocean and land with the same gain, ocean gridboxes have a systematically higher lag. This indicates that the greater lag over ocean is not only due to a higher heat capacity. The differing land and ocean behavior can most easily be seen when focusing on a single latitude band (e.g. Fig. 2c). Rather than exhibiting a land-ocean symmetry, the amount of change in lag related to a specified change in gain is dependent on whether 
gain is increasing or decreasing in the direction of the prevailing Westerlies. Notably, this second-order structure indicates that it is not possible to define a single scalar value for continentality that completely describes the annual Fourier component of the climatological annual cycle.

We seek to explain these three features of extratropical seasonality using as simple a physical model as possible.

\section{Influence of atmospheric circulation}

We aim to quantify the predictive strength of the hypothesis that the large-scale spatial structure of the annual cycle is a consequence of land-ocean coupling through atmospheric circulation. An initial scale analysis supports the idea of a dominant role for atmospheric circulation: an approximate mid-tropospheric wind speed of $10 \mathrm{~m} \mathrm{~s}^{-1}$ and a radiative relaxation time of about a month (Goody and Yung 1989) suggests that atmospheric temperature properties can be advected on scales of tens-of-thousands of kilometers. This simplistic analysis excludes latent heat processes and vertical adjustment, among other processes, but nonetheless indicates that oceanic influence can be present in continental interiors, and vice-versa. Below we quantify this influence through evaluating the Lagrangian history of air parcels over land and ocean and, subsequently, incorporating this information into an energy balance model in the spirit of North et al. (1981).

\section{a. Lagrangian trajectory analysis}

To evaluate whether the basic features of the annual cycle can be explained as the result of atmospheric circulation coupling land and ocean, we employ the NOAA Air Resources Laboratory HYbrid Single-Particle Lagrangian Integrated Trajectory (HYSPLIT) model (Draxler and Hess 1997, 1998; Draxler 1997). We estimate 9,901,440 air parcel back trajectories, where 955 trajectories were initialized at each point on a $2.5^{\circ}$ global grid. All 
back trajectories begin at 1000 meters above ground level, a rough approximation of the top of the boundary layer. Individual trajectories are equally spaced throughout 2006-2010 to obtain a representative annual average distribution of the source regions for each location (Fig. 3). Parcels are followed for the 28 days preceding their initialization, or until they go above $200 \mathrm{hPa}$, approximating the tropopause.

Fig. 3 shows three illustrative examples of the spatial distribution of the back trajectories, with parcels initialized in southeast Russia $\left(57.5^{\circ} \mathrm{N}, 117.5^{\circ} \mathrm{E}\right)$, coastal California $\left(37.5^{\circ} \mathrm{N}\right.$, $\left.122.5^{\circ} \mathrm{W}\right)$, and off the coast of Chile $\left(37.5^{\circ} \mathrm{S}, 82.5^{\circ} \mathrm{W}\right)$. Each of the seven contours encloses the $99 \%$ of air parcels that are closest to the source location in each of the seven days before initialization, indicating the extent of the source region.

\section{b. Relative Land Influence}

Using the ensemble of HYSPLIT parcel trajectories, we define Relative Land Influence, RLI, as the weighted average of land and ocean that a set of air parcels in the atmospheric column have previously passed over,

$$
R L I=\frac{1}{N} \sum_{i=1}^{N} \frac{\sum_{t=0}^{28 \text { days }} Z(t) e^{-t / \tau}}{\sum_{t=0}^{28 \text { days }} e^{-t / \tau}} .
$$

$Z(t)$ takes on values of zero or one depending on whether the parcel is over ocean or land, respectively, at time $t$, where a three hour resolution is used. $\tau$ is the globally averaged radiative relaxation time of the atmosphere, set at 25 days based on consideration of the lower $800 \mathrm{hPa}$ of the atmosphere and using an emission temperature of $255 \mathrm{~K}$ (Goody and Yung 1989). The spatial structure of RLI is largely insensitive to reasonable choices of $\tau$; e.g., the pattern using a 15 day relaxation time is correlated at $\mathrm{R}=0.99$ to the one presented here.

To classify surface type, we use the NOAA GCOS one-degree land mask ${ }^{2}$ and the ISLSCP

\footnotetext{
${ }^{2}$ Available at http://data.nodc.noaa.gov/GCOS/software/
} 
II one-degree global sea ice concentration dataset ${ }^{3}$. The land mask is constant in time but the sea ice mask is at monthly resolution. A gridbox is considered to be sea ice if its average concentration is greater than $50 \%$ for the month, and sea ice-covered gridboxes are treated as land.

A map of RLI (Fig. 4) shows the expected increase in land influence from west to east across continents and the complimentary decrease across ocean basins. The most continental region is in eastern Eurasia. No land gridbox is free from oceanic influence, and the converse. Note that values of RLI show a substantial overlap between land and ocean because ocean gridboxes off the eastern edge of continents have constituent air parcels mostly derived from over land, whereas land gridboxes on the western edge of continents are heavily influenced by oceanic conditions. This behavior is qualitatively consistent with the second feature of the annual cycle data identified in Sec. 2.

One means of converting RLI into units that can be directly compared with the gain and lag structure of the annual cycle is to define two time series for representative land and ocean annual cycles, for which we use the highest and lowest gain amongst the observed annual cycle climatologies, respectively. The land end member has a gain of $131^{\circ} \mathrm{C}\left(\mathrm{kW} \mathrm{m}^{-2}\right)^{-1}$ and a lag of 22 days, whereas the ocean end member has a gain of $5.01{ }^{\circ} \mathrm{C}\left(\mathrm{kW} \mathrm{m}^{-2}\right)^{-1}$ and a lag of 96 days. It is then possible to convert RLI into a real time series of temperature at each gridbox, $T_{\mathrm{RLI}}(x, y, m)=R L I(x, y) T_{\text {land }}(m)+(1-R L I(x, y)) T_{\text {ocean }}(m)$, where $m$ indicates month, and all temperatures are monthly averages. Albeit simplistic, this mixing model explains $84 \%$ of the space-time variance in climatological temperature, with better performance over land than ocean, where it explains $93 \%$ and $72 \%$ of the variance, respectively.

As can be seen when $T_{\mathrm{RLI}}$ is projected into components that are in phase and in quadrature with the solar annual cycle (Fig. 4b), the mixing model captures the first two features of the data: linearity and overlap. Linearity is reproduced by construction, whereas overlap results from the aforementioned properties of RLI. The non-unique relationship between gain

\footnotetext{
${ }^{3}$ Available at http://daac.ornl.gov/
} 
and lag is, however, not captured by this framework (see Fig. 4b), and this issue is returned to in the next section using a more physical model of the annual cycle. Including when the parcel has been in the upper or lower troposphere during its trajectory as an additional predictor adds little to no explanatory power with respect to the annual cycle.

The misfit between our Lagrangian metric of the annual cycle, $T_{\mathrm{RLI}}$, and the observations, $T_{\mathrm{HadCRU}}$, can be measured by the root mean square error, $\operatorname{RMSE}(\mathrm{x}, \mathrm{y})=\left(\frac{1}{12} \sum_{\mathrm{m}=1}^{12}\left(T_{\mathrm{HadCRU},(\mathrm{x}, \mathrm{y}, \mathrm{m})}-\right.\right.$ $\left.\left.\left.T_{\mathrm{RLI},(\mathrm{x}, \mathrm{y}, \mathrm{m})}\right)^{2}\right]\right)^{1 / 2}$, normalized by the amplitude of the annual Fourier component of temperature (Fig. 4c). The RMSE relative to the annual amplitude is largest in regions of sea ice cover, indicating the importance of more fully accounting for this third surface type that is neither land nor ocean in future work. The importance of sea ice has recently been demonstrated by Dwyer et al. (2012), who showed that its loss can account for changes in the amplitude and phase of the annual cycle of temperature in general circulation model simulations. Globally, the majority of the misfit results from a mis-assignment of lag in the RLI model. Holding either lag or gain constant at the observed value for all gridboxes and changing the other to that predicted by RLI indicates that the error due to lag misfits is approximately twice that due to gain misfits.

\section{Advection energy balance model}

The Relative Land Influence metric accounts for the amount of time air parcels spend over land and ocean, but does not consider the physical interactions between surface and atmosphere along a trajectory. To explain the third feature of the annual cycle, offset, we turn to an energy balance model.

\section{a. Model and idealized application}

We present a simple energy balance model with east-west resolution of an advecting atmosphere atop a surface layer, permitting calculation of both atmospheric and surface 
temperature, $T_{a}$ and $T_{s}$. The surface radiative balance is driven by absorbed shortwave radiation, $(1-\alpha)\left(1-f_{\text {abs }}\right) S(t)$, where $S(t)$ is the annual cycle of top-of-the-atmosphere incoming solar radiation at a fixed latitude, $\alpha$ is surface albedo, and $f_{a b s}$ is atmospheric absorption. $S(t)$ is time-dependent whereas $\alpha$ and $f_{a b s}$ are constant. The surface is either land or ocean, distinguished by differing heat capacities, $C_{s}$. These surfaces are coupled to the atmosphere through a "leaky greenhouse" framework, where the atmosphere absorbs and emits longwave radiation with an emissivity, $\epsilon$, as well as through a linear diffusivity term, $\kappa$, that multiplies the local surface-atmosphere temperature difference and represents non-radiative heat exchange. The atmosphere flows west-to-east with velocity $u$, and has a heat capacity $C_{a}$, that together define a horizontal scale of influence. The advection energy balance model is expressed as,

$$
\begin{aligned}
& C_{s} \frac{d T_{s}}{d t}=(1-\alpha)\left(1-f_{a b s}\right) S(t)+\kappa\left(T_{a}-T_{s}\right)+\sigma\left(\epsilon T_{a}^{4}-T_{s}^{4}\right), \\
& C_{a} \frac{\partial T_{a}}{\partial t}=-u C_{a} \frac{\partial T_{a}}{\partial x}+f_{a b s} S(t)+\kappa\left(T_{s}-T_{a}\right)+\epsilon \sigma\left(T_{s}^{4}-2 T_{a}^{4}\right) .
\end{aligned}
$$

Note that the model retains no vertical structure in either the atmosphere or ocean and that the temperatures in both can be viewed as representative of their respective mixed layers. The numerical values for all model parameters are in Table 1.

We apply the model to a simplified geometry, with constant, closed zonal flow around a latitude band consisting of one continent and one ocean basin of equal width. The modeled annual cycle along the band is shown in Fig. 5 and exhibits all three features discussed in Sec. 2: linearity, overlap, and offset. We are able to offer some perspective on the origins of the three features based on our simple model as follows:

(1) Linearity: The annual cycle in atmospheric temperature results from the relative influence of the land and ocean surfaces. The disparate heat capacities of land and ocean give differing basic annual cycles, in terms of gain and lag, that are then mixed through the advecting atmosphere. 
(2) Overlap: The advective heat fluxes are of the same order of magnitude as the surfaceatmosphere heat fluxes (Fig. 6), allowing for the penetration of remote oceanic conditions into continents, and vice-versa.

(3) Offset: Absent atmospheric circulation in the model, land surfaces and the overlying atmosphere would have an annual cycle in temperature that lagged solar radiation by about a month, whereas ocean surfaces would lag the atmosphere by about three months and the overlying atmosphere by almost as much. Transport of heat by the atmosphere, represented using a constant zonal velocity, has the counter-intuitive effect of making the lag over land smaller and that over ocean greater. This broadening of land-ocean lags appears to be at the heart of the offset, because it almost entirely disappears if the surface annual cycle is prescribed to be equal to that attained in the no atmospheric circulation case.

The increased lag over ocean can be understood through considering the influence of atmosphere-surface heat fluxes relative to solar fluxes. The annual cycle in atmospheric temperature advected off the eastern edge of the continent into the western edge of the ocean basin leads to atmosphere-surface heat fluxes having a larger magnitude than direct radiative absorption. These fluxes of heat from the atmosphere generally lag behind the solar forcing, leading to a greater ocean lag than would be the case without atmospheric advection. As the continental influence decreases eastward, the solar heat fluxes become dominant and seasonality approaches that obtained with no atmospheric circulation.

The situation differs slightly over land. The annual cycle of the atmosphere advected onto the western edge of the continent primarily acts to damp the annual cycle over land, which decreases both its gain and lag. This is in analogy with a linear system driven by periodic forcing, e.g., $C \frac{d T}{d t}=A \exp [\imath \omega t]-\lambda T$, where the lag of $T$ relative to the forcing also decreases with greater damping, $\phi=\frac{1}{\omega} \arctan \left[\frac{\omega C}{\lambda}\right]$. Thus, the oceanic influence acts to decrease the lag over land. These two effects combine to produce the lag offset in the model (e.g. Fig. 5b-e).

Examination of the modeled heat fluxes (Fig. 6) gives more insight into the controls 
on the annual cycle. The advective and surface-atmosphere heat fluxes are large and in opposition. The shortwave forcing from atmospheric absorption is small compared to the other heat fluxes, only becoming comparable in the eastern interiors of continents and ocean basins, although it becomes a more dominant heating source when considering zonal mean quantities (Donohoe and Battisti 2013). The tendency, which is proportional to but in quadrature phase with the annual cycle in temperature, is the residual of these large heat fluxes, and is generally an order of magnitude smaller than either the advective or surfaceatmosphere heat fluxes. Furthermore, because the tendency is the sum of multiple heat fluxes in addition to solar forcing, the phase of air temperature is able to have a more-than90-degree phase lag from the solar forcing.

We find the structure of the modeled annual cycle to be largely insensitive to reasonable variations in model design. For instance, although the majority of planetary albedo is due to atmospheric rather than surface reflection (Donohoe and Battisti 2011), changing this partitioning does not affect the result in the sense that the resulting amplitude and phase structure are correlated with the base case at $\mathrm{R}>0.99$. Including a seasonally-variable emissivity and varying albedo spatially or seasonally based on observations from the Earth Radiation Budget Experiment (Barkstrom 1984) also has negligible influence on our results. Varying the coupling constant, $\kappa$, between 10 and $50 \mathrm{~W} \mathrm{~m}^{-2} \mathrm{~K}^{-1}$ has a slightly larger effect, particularly on the rate of change of lag across ocean basins, but the general structure is retained, and the gain and lag between the base case and these other choices for $\kappa$ are correlated with $\mathrm{R} \geq 0.97$ and $\mathrm{R} \geq 0.89$, respectively.

The zonal flow model can also be applied to the land-ocean configuration of a specific latitude band, for which we choose $45-50^{\circ} \mathrm{N}$, and compared to the observed annual cycle there (Fig. 7c, d). The model captures the first-order structures in gain and lag over ocean and land but does not reproduce differences such as those between North American and Eurasia. The misfit between the model and the observations can likely be ascribed to two obvious and related oversimplifications in the zonal flow model: the prescription of constant 
velocity for the full latitude band and the use of the fixed land-ocean configuration at that latitude band, as opposed to taking into account differences in surface type that would result if the circulation was not purely zonal.

\section{b. Incorporation of HYSPLIT results}

To explore the idea that model mismatch arises because of deviations from pure zonal flow, we incorporate HYPSPLIT parcel trajectories. Consider a single trajectory that arrives at a single gridbox of the zonal model, for which we are interested in estimating the annual cycle. We construct a separate model to represent the 28 days preceding its arrival at the gridbox, using the land-ocean sequence that the trajectory follows as the surface type boundary condition in the model. Land and ocean boxes are determined from position using the GCOS one-degree land mask, and model velocity, $u$, is specified as the average zonal velocity of the trajectory. All other model parameters are in Table 1 and are identical to those used in the idealized simulation in the previous section. To capture the full seasonal cycle, the model is integrated to steady seasonality using solar forcing, $S(t)$ (as in Eqns. (2) and (3)). The initial condition for the air parcel comes from the closed-loop zonal flow model after also integrating it to a steady annual cycle under the same model parameters.

To sample a larger fraction of the distribution of parcel source regions (e.g. Fig. 3), we integrate the model using 642 different trajectory paths for each of the 72 five-degree gridboxes in the latitude band between $45-50^{\circ} \mathrm{N}$. Trajectories are equally spaced across the time period 2006-2010 and are a subset of those used to calculate Relative Land Influence. The energy balance model outputs across each trajectory are then averaged to create a climatology for comparison to observations.

The model climatology captures $94 \%$ of the space-time variance of the monthly temperature climatologies in the latitude band considered (Fig. 7a), including the more rapid changes in lag across ocean than land, the rapid decrease in gain at the western edge of the Pacific Ocean, and the more rapid increase in gain across North America than Eurasia. The energy 
balance model that incorporates the HYSPLIT information captures basin-scale features substantially better than is the case when a constant zonal flow is assumed (Fig. 7c,d).

The primary model-data misfit arises from the model producing too large a lag in the interiors of ocean basins, and we speculate this is due to lack of model mixed layer dynamics (e.g. Laepple and Lohmann 2009). One might also have suspected that major features of the annual cycle would be controlled by processes such as temporal and spatial variability in cloudiness (Weaver and Ramanathan 1997), intra-annual variability in atmospheric circulation patterns (Stine and Huybers 2012), moisture availability over land (Stine et al. 2009), or higher order Fourier components of the annual cycle (Legates and Willmott 1990). These additional processes presumably also contribute, but the present results indicate that the primary explanation for spatial variability in the the extratropical annual cycle structure is the land-ocean contrast, mediated by the circulation of the atmosphere.

\section{Conclusion}

The extratropical annual cycle is characterized by (1) a first-order linear structure consistent with an end-member mixing framework, (2) a land-ocean overlap in gain and lag, and (3) a systematically higher lag over ocean than land. Previous analysis identified feature (1) as due to relative land and ocean influences (Stine et al. 2009). We further find that accounting for the source region of air parcels through a Lagrangian approach captures feature (2), and that combining atmospheric advection with an energy balance model captures feature (3). Each component of our simple model appears necessary for describing these three features, suggesting that it is, in a sense, a minimal representation. Atmospheric coupling between land and ocean gives rise to a linear structure between gain and lag when plotted in polar coordinates, the directional nature of atmospheric advection leads to overlap in gain and lag, and the time-dependence of atmospheric interaction with land and ocean produces a non-unique relationship between gain and lag. 
These results support previous findings and have several further implications. Changes in continental configuration over geological timescales are expected to have far-reaching effects on the annual cycle, as the air parcel source region for a given location will become more continental or oceanic. Loss of sea ice (e.g. Stroeve et al. 2012) is also expected to moderate nearby annual cycles due to an increase in effective heat capacity (Dwyer et al. 2012). Further work on the parameterization of sea ice in this framework may be helpful in understanding the connection between sea ice loss and changes in the annual cycle. Finally, the coupling of land and ocean via mean circulation patterns is not specific to annual period variability, and this framework may also provide insight into the magnitude and timing of changes at synoptic and interannual timescales.

Acknowledgments.

We thank Andrew Rhines for assistance in running HYSPLIT and helpful discussions, and Aaron Donohoe for his constructive review and subsequent communications. KAM was supported by the NSF GRFP, and ARS and PJH by NSF grant 0902374. 


\section{REFERENCES}

Barkstrom, B. R., 1984: The earth radiation budget experiment (ERBE). Bulletin of the American Meteorological Society, 65 (11), 1170-1185.

Berger, A. and M. Loutre, 1991: Insolation values for the climate of the last 10 million years. Quaternary Science Reviews, 10 (4), 297-317.

Brooks, C., 1917: Continentality and temperature. Quarterly Journal of the Royal Meteorological Society, 43 (182), 159-174.

Brooks, C., 1918: Continentality and temperaturesecond paper: The effect of latitude on the influence of continentality on temperature. Quarterly Journal of the Royal Meteorological Society, 44 (188), 253-270.

Brunt, D., 1924: Climatic continentality and oceanity. The Geographical Journal, 64 (1), 43-49.

Donohoe, A. and D. S. Battisti, 2011: Atmospheric and surface contributions to planetary albedo. Journal of Climate, 24 (16), 4402-4418.

Donohoe, A. and D. S. Battisti, 2013: The seasonal cycle of atmospheric heating and temperature. Journal of Climate, doi:10.1175/JCLI-D-12-00713.1, URL http://dx .doi .org/ 10.1175/JCLI-D-12-00713.1.

Draxler, R., 1997: HYSPLIT4 user's guide. NOAA Tech. Memo ERL ARL-230, NOAA Air Resources Laboratory, Silver Spring, MD.

Draxler, R. and G. Hess, 1997: Description of the HYSPLIT_4 modeling system. NOAA Tech. Memo ERL ARL-224, NOAA Air Resources Laboratory, 24 pp., Silver Spring, MD. 
Draxler, R. and G. Hess, 1998: An overview of the HYSPLIT_4 modelling system for trajectories, dispersion, and deposition. Australian Meteorological Magazine, 47 (4), 295-308.

Dwyer, J., M. Biasutti, and A. Sobel, 2012: Projected changes in the seasonal cycle of surface temperature. Journal of Climate, 25 (18), 6359-6374.

Goody, R. and Y. Yung, 1989: Atmospheric Radiation: Theoretical Basis. 2d ed., Oxford University Press, New York.

Hela, I., 1953: Regional distribution of the continentality in the climate of the oceans. Geophysica, 4 (2), 41-47.

Hyde, W. T., T. J. Crowley, K.-Y. Kim, and G. R. North, 1989: Comparison of GCM and Energy Balance Model Simulations of Seasonal Temperature Changes over the Past 18000 Years. Journal of Climate, 2, 864-887.

Kim, K.-Y. and G. R. North, 1992: Seasonal Cycle and Second-Moment Statistics of a Simple Coupled Climate Model. Journal of Geophysical Research, 97 (D18), 20 437-20 448.

Laepple, T. and G. Lohmann, 2009: Seasonal cycle as template for climate variability on astronomical timescales. Paleoceanography, 24 (4), PA4201.

Legates, D. and C. Willmott, 1990: Mean seasonal and spatial variability in global surface air temperature. Theoretical and Applied Climatology, 41 (1), 11-21.

Menne, M., I. Durre, R. Vose, B. Gleason, and T. Houston, 2012: An overview of the global historical climatology network-daily database. Journal of Atmospheric and Oceanic Technology, 29 (7), 897-910.

Morice, C. P., J. J. Kennedy, N. A. Rayner, and P. D. Jones, 2012: Quantifying uncertainties in global and regional temperature change using an ensemble of observational estimates: The HadCRUT4 data set. Journal of Geophysical Research, 117 (D8), D08 101. 
North, G. R., R. F. Cahalan, and J. A. Coakley, 1981: Energy balance climate models. Reviews of Geophysics and Space Physics, 19 (1), 91-121.

North, G. R. and J. A. Coakley, 1979: Differences between seasonal and mean annual energy balance model calculations of climate and climate sensitivity. Journal of the Atmospheric Sciences, 36, 1189-1204.

North, G. R., J. G. Mengel, and D. A. Short, 1983: Simple Energy Balance Model Resolving the Seasons and the Continents: Application to the Astronomical Theory of the Ice Ages. Journal of Geophysical Research, 88 (C11), 6576-6586.

Prescott, J. and J. Collins, 1951: The lag of temperature behind solar radiation. Quarterly Journal of the Royal Meteorological Society, 77 (331), 121-126.

Spitaler, R., 1922: Klimatische kontinentalität und ozeanität. Petermanns Geographische.

Stine, A. and P. Huybers, 2012: Changes in the seasonal cycle of temperature and atmospheric circulation. Journal of Climate, 25 (21), 7362.

Stine, A., P. Huybers, and I. Fung, 2009: Changes in the phase of the annual cycle of surface temperature. Nature, 457 (7228), 435-440.

Stroeve, J., M. Serreze, M. Holland, J. Kay, J. Malanik, and A. Barrett, 2012: The Arctic's rapidly shrinking sea ice cover: a research synthesis. Climatic Change, 1-23.

Thompson, R., 1995: Complex demodulation and the estimation of the changing continentality of europe's climate. International journal of climatology, 15 (2), 175-185.

Thompson, S. L. and S. H. Schneider, 1979: A Seasonal Zonal Energy Balance Climate Model With an Interactive Lower Layer. Journal of Geophysical Research, 84 (C5), 2401.

van den Dool, H. and G. Können, 1981: Strong variations in the delay of the annual cycle in the air temperature near the coast. First International Conference on Meteorology and 
Air/Sea Interaction of the Coastal Zone, Boston, MA, American Meteorological Society, $325-327$.

Von Hann, J. and R. Ward, 1903: Handbook of climatology. The MacMillan Company, New York.

Ward, R., 1906: The classification of climates: I. Bulletin of the American Geographical Society, 38 (7), 401-12.

Weaver, C. and V. Ramanathan, 1997: Relationships between large-scale vertical velocity, static stability, and cloud radiative forcing over northern hemisphere extratropical oceans. Journal of climate, 10 (11), 2871-2887. 


\section{${ }_{440}$ List of Tables}

441 1 Parameter values for the advection model. Zonal wind velocity is the average 
TABLE 1. Parameter values for the advection model. Zonal wind velocity is the average across the HYSPLIT trajectories at $45-50^{\circ} \mathrm{N}$; see Sec. $4 \mathrm{~b}$.

\begin{tabular}{lccc}
\hline \hline Name & Var. name & Value & Units \\
\hline Zonal wind velocity & $\mathrm{u}$ & 6.1 & $\mathrm{~m} \mathrm{~s}^{-1}$ \\
Emissivity & $\epsilon$ & 0.8 & \\
Albedo & $\alpha$ & 0.3 & \\
Coupling coefficient & $\kappa$ & 50 & $\mathrm{~W} \mathrm{~m}^{-2} \mathrm{~K}^{-1}$ \\
Shortwave absorption & $f_{a b s}$ & 0.18 & \\
Ocean heat capacity & $C_{o}$ & 75 & $\mathrm{~m} . w . e$. \\
Land heat capacity & $C_{l}$ & 1 & m.w.e. \\
Atmosphere heat capacity & $C_{a}$ & 1 & $\mathrm{~m} . w . e$. \\
meter-water-equivalent & m.w.e. & $4.18 \times 10^{6}$ & $\mathrm{~J} \mathrm{~m} \mathrm{~m}^{-2} \mathrm{~K}^{-1}$ \\
Latitude & & $47.5^{\circ} \mathrm{N}$ & \\
\hline
\end{tabular}




\section{List of Figures}

1 (a) Gain and (b) lag of the annual Fourier component of the climatological annual cycle.

2 The gain and lag of the annual cycle in polar coordinates in the (a) Northern and (b) Southern Hemispheres, and (c) at $45-50^{\circ}$ N. In (c), neighboring gridboxes are connected via a thin gray line to illustrate the connection between the pattern in map view and in polar coordinates. Black X's indicate land, and gray O's indicate ocean. Contours of equal gain $(G)$ and lag $(\lambda)$ are the labeled concentric circles and lines emanating from the origin, respectively.

3 Source regions for parcels at the yellow ' $\mathrm{x}$ '. Each of the seven consecutively larger areas enclosed by the contour lines contains the closest $99 \%$ of parcel locations for each of seven days before initialization of the back trajectories.

(a) Relative Land Influence (RLI) calculated from the HYSPLIT trajectory paths using Eq. (1). (b) Gain and lag of the annual cycle from the RLIweighted end member mixing model (black) and, for comparison, the data (gray). (c) The root mean square error between the model and the data, normalized by the local amplitude of the annual Fourier component in temperature. 27 (a) Gain and lag of the annual cycle in polar coordinates calculated from the advection energy balance model (Eqs. (2) and (3)) using an idealized geometry. Black X's indicate land, gray O's indicate ocean. Neighboring gridboxes of the same surface type are connected by a thin gray line, and arrows indicate west-to-east movement across longitude. (b)-(e) Modeled annual cycles for the atmosphere atop land (b, d) and ocean (c, e) at the locations marked by black stars in (a). 'Atmosphere (in)' is the annual cycle of the atmosphere for the gridbox immediately to the west. The amplitude is the same in each row, but the ocean points exhibit a greater lag than the land points by 52 (b, c) and $21(\mathrm{~d}, \mathrm{e})$ days. 
6 The amplitude and phase of the heat fluxes to the atmosphere in the advection energy balance model shown in polar coordinates. (a) Energy flux amplitude and phase broken down into components: advective $\left(-u C_{a} \frac{\partial T_{a}}{\partial x}\right.$, light blue); sensible, latent, and longwave $\left(\kappa\left(T_{s}-T_{a}\right)+\epsilon \sigma\left(T_{s}^{4}-2 T_{a}^{4}\right)\right.$, red $)$; and solar $\left(f_{a b s} S(t)\right.$, yellow star). Mathematical representations correspond to Eqn. (3). X's indicate land, O's indicate ocean, neighboring gridboxes of the same surface type are connected by a thin gray line, and arrows indicate west-to-east movement across longitude. (b) Net heating (orange, $\mathrm{Wm}^{-2}$ ) and the normalized temperature response $\left(\right.$ dark red, $\left.{ }^{\circ} \mathrm{C}\left(\mathrm{kW} \mathrm{m}^{-2}\right)^{-1}\right)$. The normalized temperature response is multiplied by a value of 0.2 to plot on the same axes as net heating.

7 (a) Monthly temperature anomalies in the latitude band $45-50^{\circ} \mathrm{N}$ from the advection model driven by HYSPLIT trajectories versus observations. (b) The gain and lag of the modeled annual cycle in polar coordinates showing land (X's) and ocean (O's) boxes. Neighboring gridboxes are connected via a thin gray line. (c) The gain of the modeled annual cycle across longitude at $45-50^{\circ} \mathrm{N}$ using a zonal wind (gray) and with the inclusion of the HYSPLIT trajectory information (black), as compared to the observations (dashed). Land regions are indicated by shading. (d) Similar to (c) but for lag. 


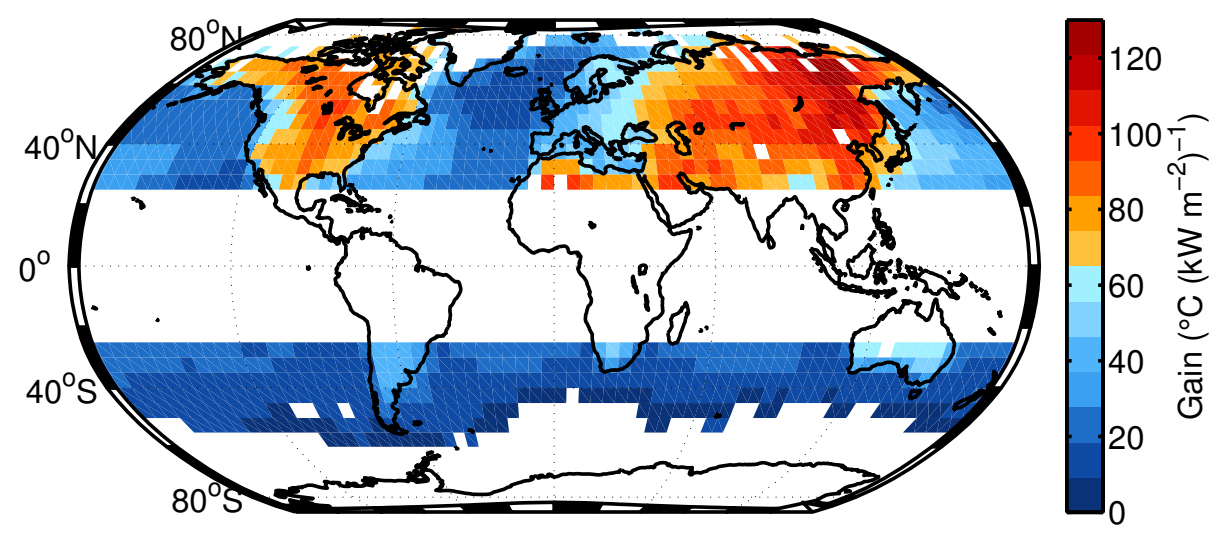

(a)

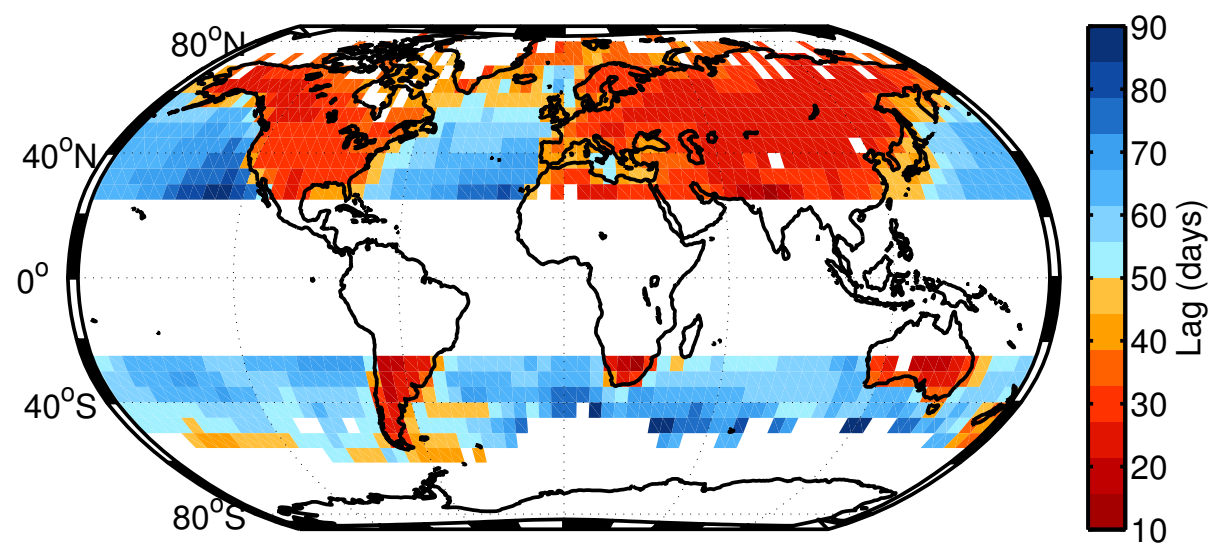

(b)

Fig. 1. (a) Gain and (b) lag of the annual Fourier component of the climatological annual cycle. 

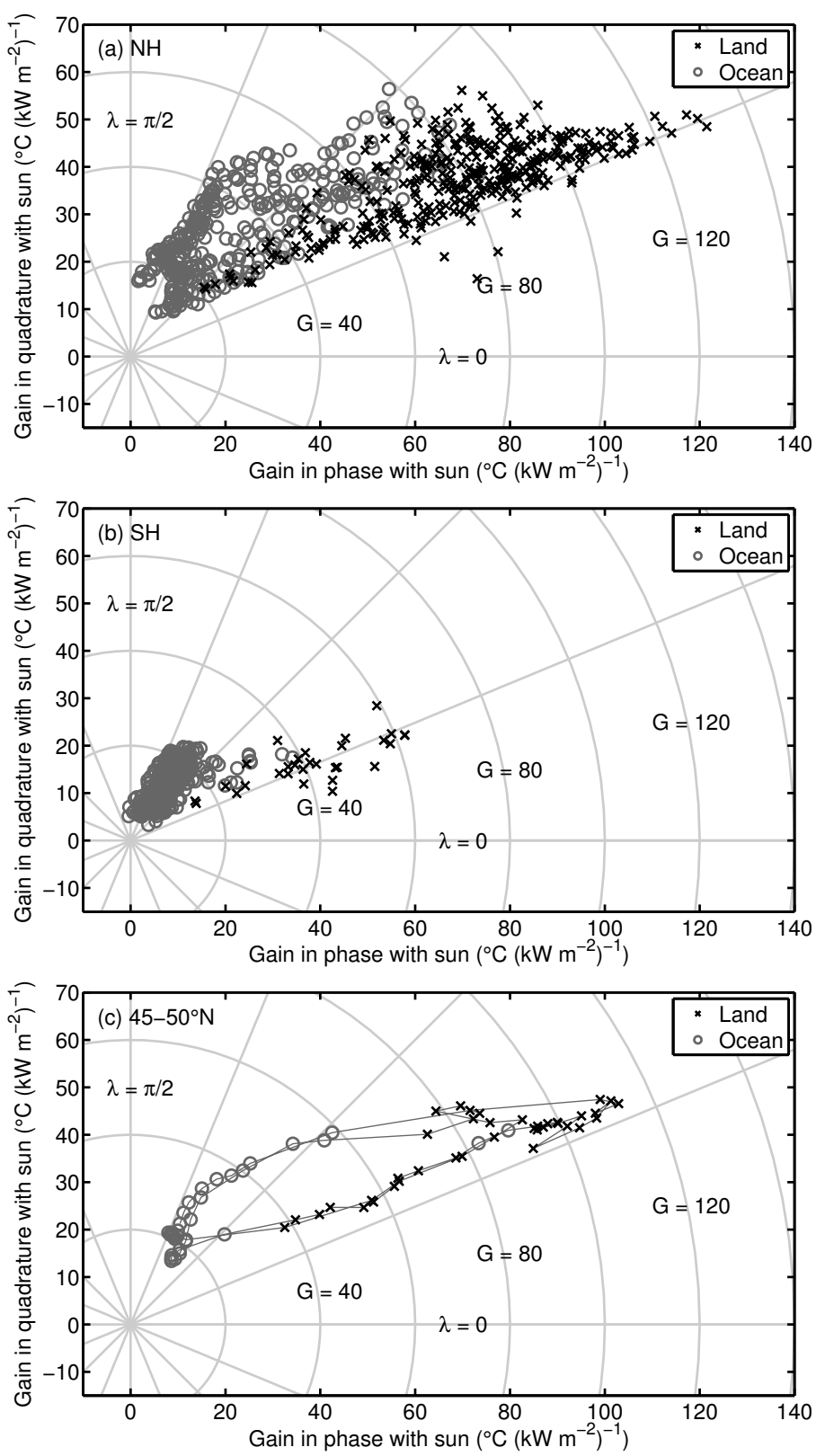

Fig. 2. The gain and lag of the annual cycle in polar coordinates in the (a) Northern and (b) Southern Hemispheres, and (c) at $45-50^{\circ}$ N. In (c), neighboring gridboxes are connected via a thin gray line to illustrate the connection between the pattern in map view and in polar coordinates. Black X's indicate land, and gray O's indicate ocean. Contours of equal gain $(\mathrm{G})$ and lag $(\lambda)$ are the labeled concentric circles and lines emanating from the origin, respectively. 


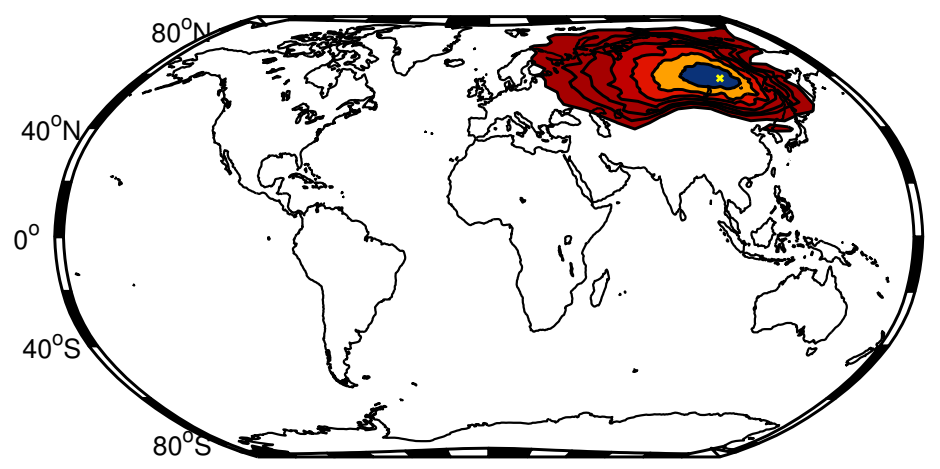

(a)

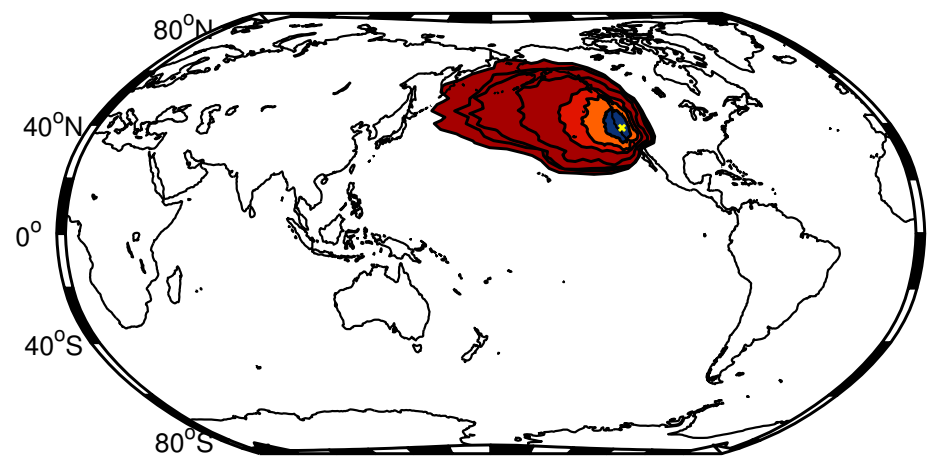

(b)

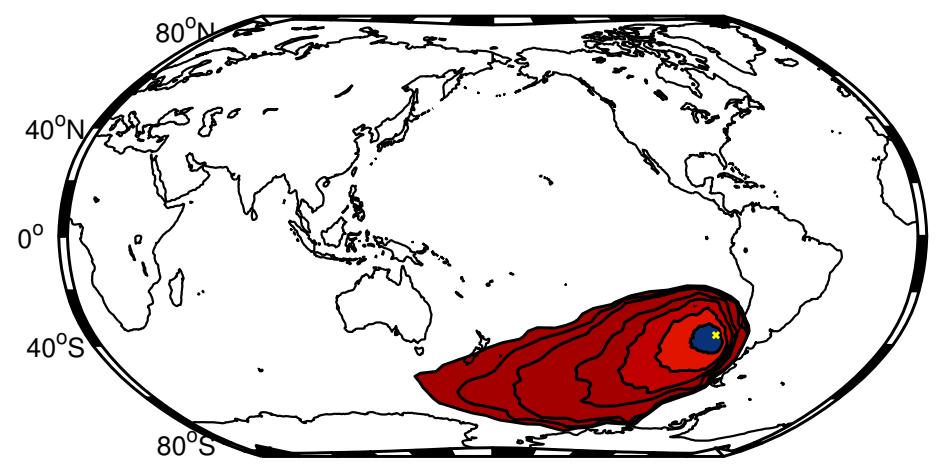

(c)

FIG. 3. Source regions for parcels at the yellow ' $x$ '. Each of the seven consecutively larger areas enclosed by the contour lines contains the closest $99 \%$ of parcel locations for each of seven days before initialization of the back trajectories. 


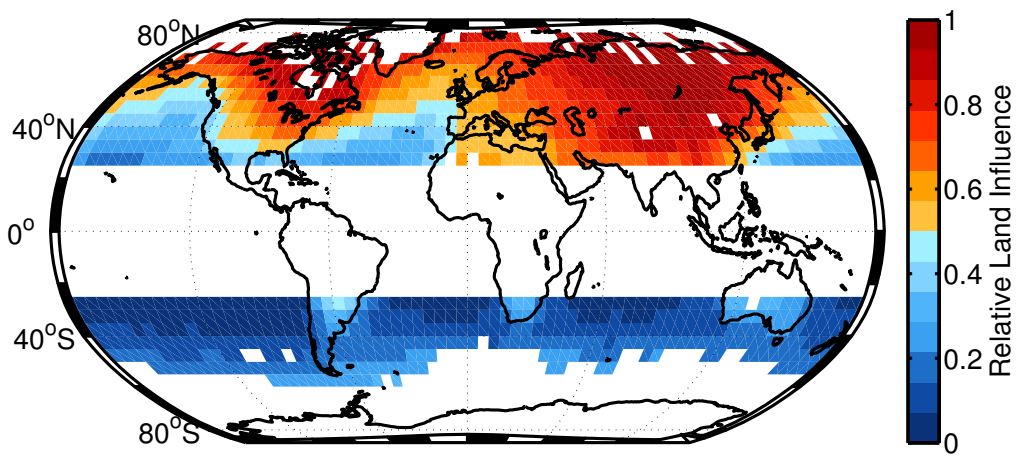

(a)
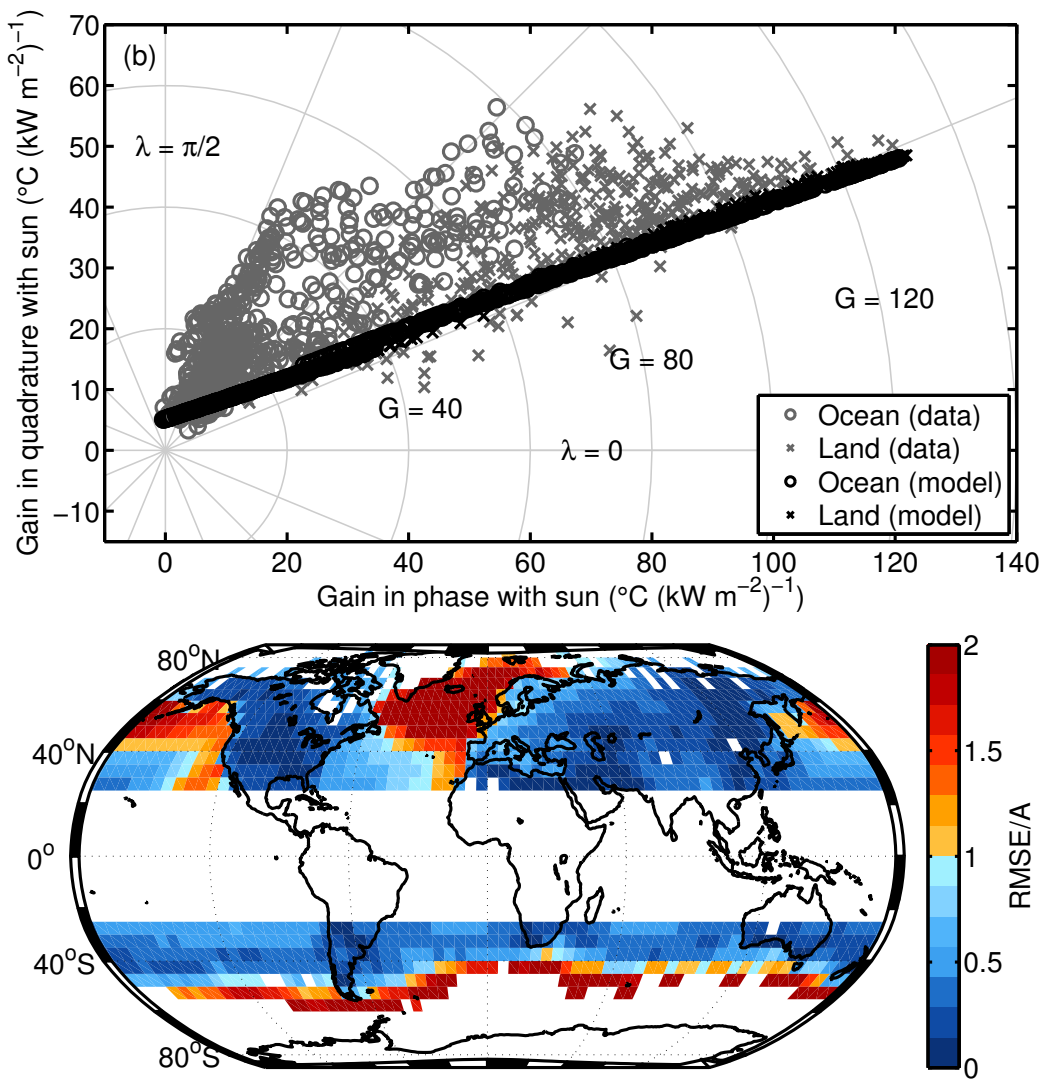

(c)

FIG. 4. (a) Relative Land Influence (RLI) calculated from the HYSPLIT trajectory paths using Eq. (1). (b) Gain and lag of the annual cycle from the RLI-weighted end member mixing model (black) and, for comparison, the data (gray). (c) The root mean square error between the model and the data, normalized by the local amplitude of the annual Fourier component in temperature. 

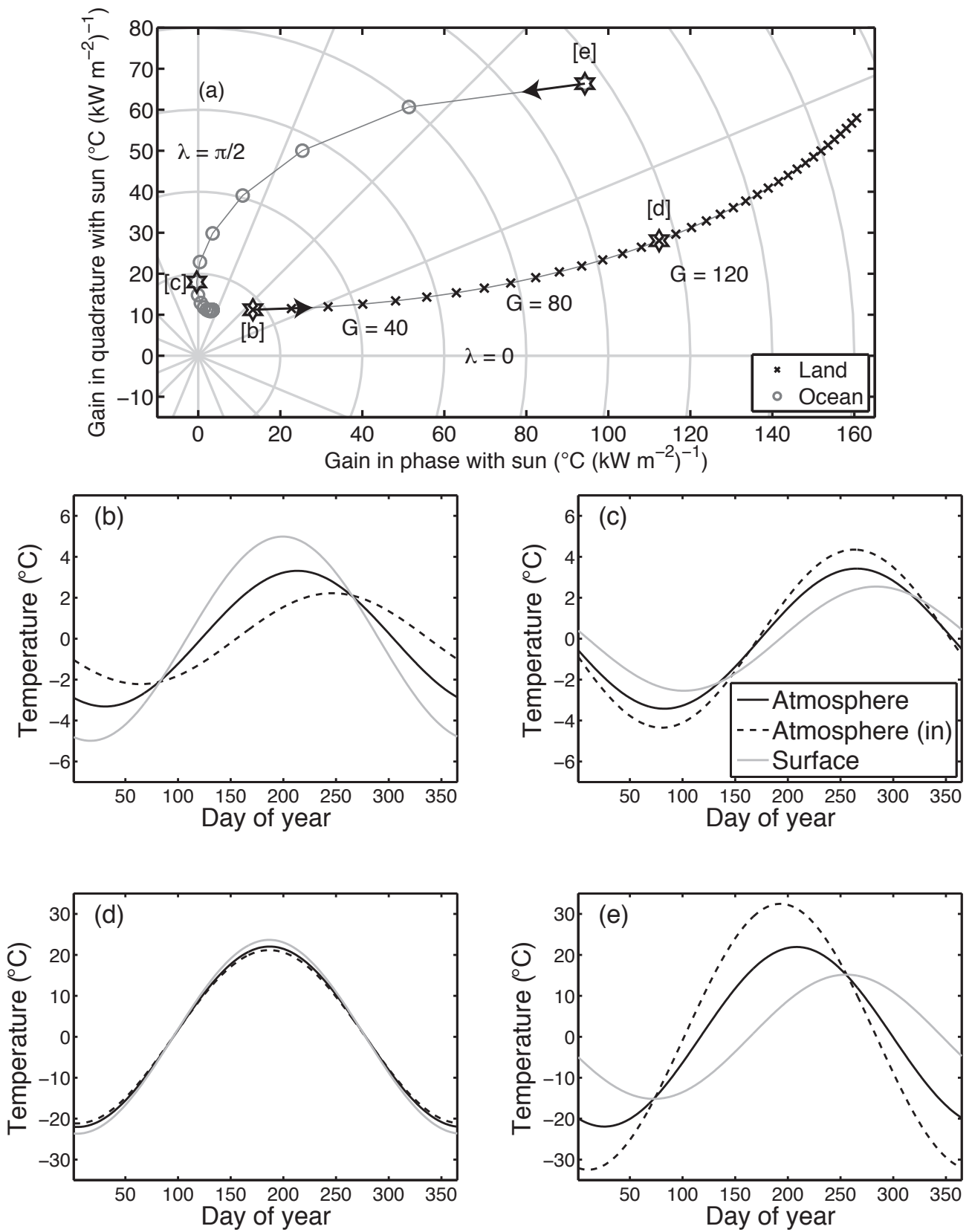

FIG. 5. (a) Gain and lag of the annual cycle in polar coordinates calculated from the advection energy balance model (Eqs. (2) and (3)) using an idealized geometry. Black X's indicate land, gray O's indicate ocean. Neighboring gridboxes of the same surface type are connected by a thin gray line, and arrows indicate west-to-east movement across longitude. (b)-(e) Modeled annual cycles for the atmosphere atop land (b, d) and ocean (c, e) at the locations marked by black stars in (a). 'Atmosphere (in)' is the annual cycle of the atmosphere for the gridbox immediately to the west. The amplitude is the same in each row, but the ocean points exhibit a greater lag than the land points by 52 (b, c) and 21 (d, e) days. 

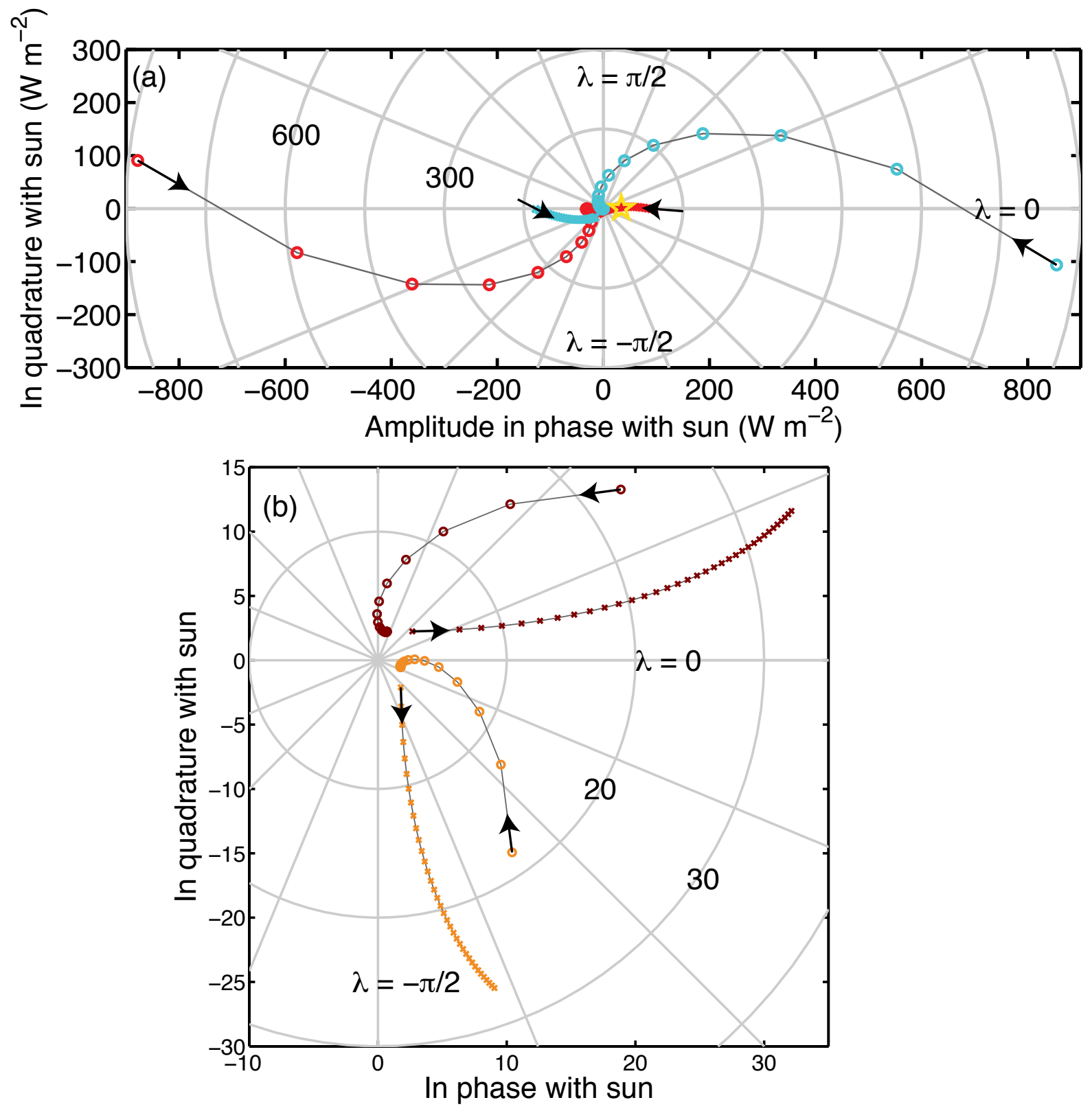

FIG. 6. The amplitude and phase of the heat fluxes to the atmosphere in the advection energy balance model shown in polar coordinates. (a) Energy flux amplitude and phase broken down into components: advective $\left(-u C_{a} \frac{\partial T_{a}}{\partial x}\right.$, light blue); sensible, latent, and longwave $\left(\kappa\left(T_{s}-T_{a}\right)+\epsilon \sigma\left(T_{s}^{4}-2 T_{a}^{4}\right)\right.$, red $)$; and solar $\left(f_{a b s} S(t)\right.$, yellow star $)$. Mathematical representations correspond to Eqn. (3). X's indicate land, O's indicate ocean, neighboring gridboxes of the same surface type are connected by a thin gray line, and arrows indicate west-to-east movement across longitude. (b) Net heating (orange, $\mathrm{Wm}^{-2}$ ) and the normalized temperature response (dark red, $\left.{ }^{\circ} \mathrm{C}\left(\mathrm{kW} \mathrm{m}^{-2}\right)^{-1}\right)$. The normalized temperature response is multiplied by a value of 0.2 to plot on the same axes as net heating. 

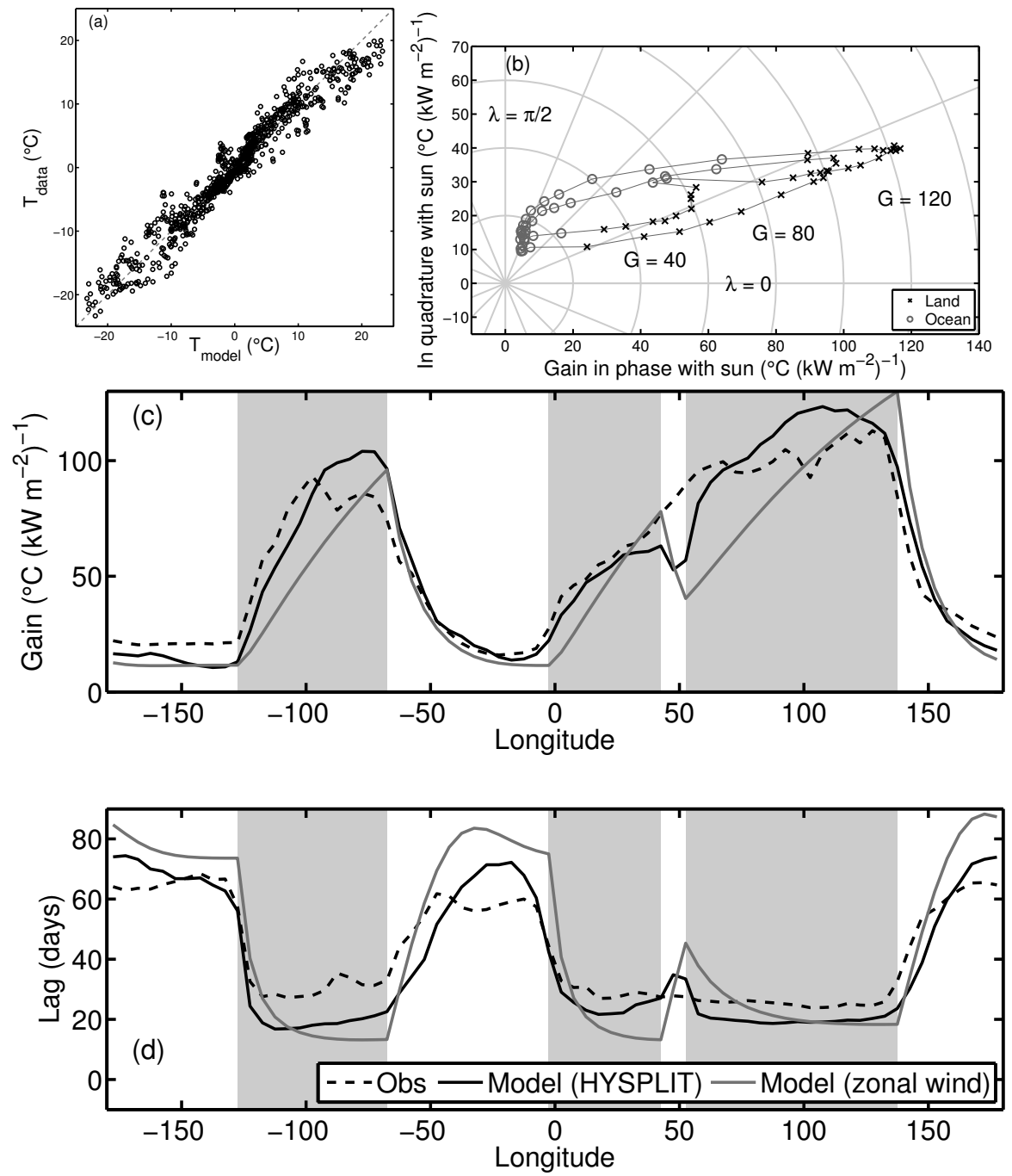

Fig. 7. (a) Monthly temperature anomalies in the latitude band $45-50^{\circ} \mathrm{N}$ from the advection model driven by HYSPLIT trajectories versus observations. (b) The gain and lag of the modeled annual cycle in polar coordinates showing land (X's) and ocean (O's) boxes. Neighboring gridboxes are connected via a thin gray line. (c) The gain of the modeled annual cycle across longitude at $45-50^{\circ} \mathrm{N}$ using a zonal wind (gray) and with the inclusion of the HYSPLIT trajectory information (black), as compared to the observations (dashed). Land regions are indicated by shading. (d) Similar to (c) but for lag. 